\title{
NOTICIARIO
}

\section{El enterramiento múltiple, calcolítico, de Camino del Molino (Caravaca, Murcia). Metodología y primeros resultados de un yacimiento excepcional}

\author{
The collective chalcolithic burial of Camino del Molino (Caravaca de la Cruz, Murcia, \\ Spain). Methodology and the first results of an exceptional archaeological site
}

\author{
Joaquín Lomba Maurandi (*) \\ Mariano López Martínez (**) \\ Francisco Ramos Martínez (**) \\ Azucena Avilés Fernández (**)
}

\section{RESUMEN}

Se presentan los resultados preliminares de la excavación de un enterramiento múltiple en cueva que contiene restos de más de 1300 individuos, en lo que parece ser la representación completa de una población calcolítica de la segunda mitad del III milenio a.C. depositada durante un período continuado de unos 350-400 años. Una pequeña parte de esa población se acompaña de un ajuar que incluye, entre otros elementos, algunos elementos metálicos característicos del horizonte campaniforme. También se documenta el enterramiento de cánidos acompañando a diversos inhumados. El carácter excepcional del hallazgo y las circunstancias de la excavación han obligado a un desarrollo metodológico novedoso para este tipo de actuaciones.

\footnotetext{
ABSTRACT

The preliminary results of the excavation of a multiple burial cave are presented. It contains remains of more than 1,300 individuals, in what it seems to be the complete representation of a chalcolithic population of the

(*) Área de Prehistoria, Dpto. de Prehistoria, Arqueología, Historia Antigua, Historia Medieval y CC.TT. Hcas, Facultad de Letras, Universidad de Murcia. Campus de la Merced. Santo Cristo 1. 30001 Murcia. Correo electrónico: jlomba@um.es

(**) Arqueología y Diseño Web S.L. (Grupo Entorno). Floridablanca $14.1 .^{\circ}$ D. 30800 Lorca. Murcia.

Correos electrónicos: marianolopez@arqueoweb.com;

franciscoramos@arqueoweb.com; azuavi@arqueoweb.com

Recibido: 6-IV-2009; aceptado: 1-IX-2009.
}

second half of the third millenium B.C. deposited during a continuous period of approximately 450 years. A small part of this population is accompanied by grave goods that include some metallic elements typical of the bell-beaker horizon. Also dogs accompanyied various burials. The exceptional character of the find and the circumstances of the excavation required the development of a new methodology for this type of excavation.

Palabras clave: Calcolítico; Enterramiento; Campaniforme; Radiocarbono; Sureste peninsular; Murcia; Cánidos; Ritual funerario.

Key words: Chalcolithic; Burial grave; Bell-beaker; Radiocarbon; Southeast Spain; Murcia; Dogs; Ritual grave.

\section{INTRODUCCIÓN}

El yacimiento de Camino del Molino (Caravaca, Murcia) se localizó de manera fortuita durante las obras de una promoción de viviendas en el perímetro suroriental de la expansión urbana de $\mathrm{Ca}$ ravaca, en diciembre de 2007 (1). Inmediatamen-

(1) No sería justo obviar la encomiable actitud y buena disposición del promotor de las obras en las que se localizó el yacimiento, D. Pedro Antonio Robles, quien no sólo paró inmediatamente la obra e informó del hallazgo a las autoridades sino que, más allá de su obligación como ciudadano, asumió la cubrición y cerramiento del yacimiento para su ulterior excavación, así como numerosos gastos directamente relacionados con los trabajos de campo, tanto de contratación de personal como de alojamiento de parte del equipo. 
te se diseñó un proyecto de actuación que se acomodara a las necesidades de una excavación de urgencia de un enterramiento calcolítico múltiple caracterizado por la presencia de una gran cantidad de evidencias antropológicas, iniciándose los trabajos de excavación en febrero de 2008 y prolongándose hasta finales de noviembre del mismo año (2).

La cantidad de restos antropológicos y su concentración espacial, la entidad y variedad del registro (ajuares, zooarqueología, antracología, etc.) $\mathrm{y}$ el hecho de encontrarse el yacimiento sujeto a una fuerte presión urbanística, obligó a la aplicación de una metodología muy específica que afectaba tanto al trabajo de campo como a la previsión de esfuerzos investigadores que cubrieran unas necesidades sin duda especiales, orientadas sobre todo a un registro muy detallado y preciso del yacimiento.

El equipo se estructuró en varios niveles, diferenciándose la actuación directa sobre el yacimiento de las tareas de laboratorio relacionados con él. Así, los trabajos de campo han pivotado alrededor de la presencia continua en el lugar de una antropóloga y dos técnicos arqueólogos, además de un número variable de operarios y estudiantes; durante la excavación se han retirado del yacimiento muestras para análisis palinológico y antracológico, edafología y sedimentología; se han tomado anotaciones de tipo geológico y geomorfológico; y se han derivado a diferentes especialistas los estudios sobre restos faunísticos, huellas de uso en utillaje, análisis de dieta, presencia de parásitos, detección de enfermedades en restos de médula ósea, etc. El estudio antropológico se lleva a cabo por una de las firmantes de este trabajo, con la colaboración de diversos especialistas (3).

(2) Los trabajos de campo se sufragaron mediante diferentes aportaciones de la Dirección General de Bellas Artes y Bienes Culturales de la Comunidad Autónoma de la Región de Murcia, el Excmo. Ayuntamiento de Caravaca de la Cruz, el propio promotor de las viviendas que se iban a construir en el lugar, y la Universidad de Murcia.

(3) Los citados estudios corren a cargo de los diferentes investigadores: palinología (Dr. Carrión Martínez, área de Botánica, UMU); edafología y sedimentología (Dra. Delgado Iniesta, área de Edafología, UMU); geología y geomorfología (Dres. Rodríguez Estrella, UPCT, y Belmonte Serrato, UMU); restos faunísticos (Dres. Vázquez Autón y Gil Cano, área de Anatomía y Embriología Animal, UMU); antracología (Dña. M. ${ }^{a}$ Soledad García Martínez, área de Botánica, UMU); huellas de uso en lítica, ósea y metal (Dra. Gutiérrez Sáez, UAM, y D. Ignacio Martín Lerma, UNED-Madrid); restos parasitológicos (Dr. A. Osuna Carrillo-Albornoz, Universidad de

\section{LOCALIZACIÓN Y CARACTERIZACIÓN DEL YACIMIENTO}

El yacimiento de Camino del Molino consiste en un enterramiento múltiple calcolítico definido por una cavidad con una planta circular de unos $7 \mathrm{~m}$ de diámetro y paredes ligeramente acampanadas, de la que se han conservado en torno a los $2 \mathrm{~m}$ inferiores en los que se acumulaba, prácticamente intacto, el depósito arqueológico. La mitad superior de la cavidad desapareció a inicios del siglo XX durante las tareas de aterrazamiento de la zona para su explotación agrícola, con la fortuna de que aparentemente esa destrucción sólo afectó a la cubierta del enterramiento, pero no a su depósito. El hallazgo se produjo cuando una pala de grandes dimensiones afectó a un sector lateral de la cueva, suponiendo dicha intervención la destrucción de no más del $15 \%$ del yacimiento.

Aunque el estudio geomorfológico indica que la oquedad formó parte de una cavidad natural en los travertinos, tanto en las paredes como en la superficie del suelo se observan huellas claras de modificación antrópica de la cueva, de manera que las paredes aparecían regularizadas en varios sectores, mientras que el suelo se encontraba claramente piqueteado.

A $400 \mathrm{~m}$ de distancia se localiza el poblado calcolítico de Molinos de Papel (Lám. I), un hábitat configurado por cabañas circulares con zócalo de piedra y gran cantidad de silos excavados sobre el mismo cerro de travertinos en cuya ladera se sitúa el enterramiento y en torno al cual el río Argos dibuja un meandro. Diversas actuaciones en el casco urbano (Pujante 1999, y otras en curso) han documentado las estructuras referidas, relacionadas con materiales calcolíticos entre los que se incluyen punzones de sección cuadrada, cerámica campaniforme y objetos de marfil, además de algún enterramiento aislado amortizando antiguas estructuras de uso doméstico excavadas en el suelo. La industria lítica del poblado, con un fuerte componente tabular, abundancia de láminas fragmentadas y puntas de flecha mayoritariamente foliáceas y con aletas muy desarrolladas,

\footnotetext{
Granada); estudios de médula ósea vinculados a la detección de enfermedades (Dra. Galán Puchades, Universidad de Valencia); análisis de dieta (Dr. Trancho, UCM); y estudio de isótopos estables. Por último, se ha contado continuamente con el asesoramiento de los Dres. Walker, antropólogo, y E. Osuna CarrilloAlbornoz, médico forense, ambos de la Universidad de Murcia, para cuestiones relacionadas con sus respetivas disciplinas.
} 


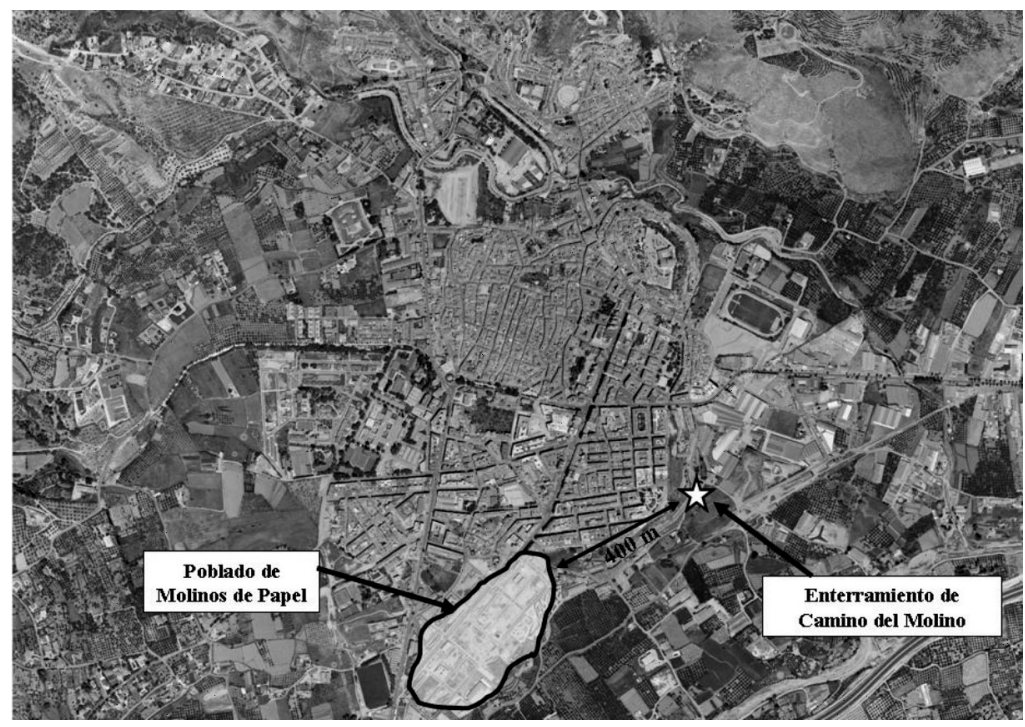

Lám. I. Fotografía aérea de Caravaca de la Cruz, con ubicación del hábitat (Molinos de Papel) y enterramiento (Camino del Molino) calcolíticos.

ofrece grandes similitudes con la encontrada en el enterramiento.

\section{METODOLOGÍA DE EXCAVACIÓN}

Tras la delimitación en planta y alzado de la fosa, realizada de manera inmediata a su hallazgo (Lám. II), se procedió a su cubrición temporal con una capa plástica que preservara los restos mien- tras se diseñaban las estrategias de excavación y se erigía una estructura permanente que permitiese continuar los trabajos de forma ininterrumpida.

La enorme cantidad de evidencias antropológicas en superficie, la previsión de que dicha densidad continuara en toda la secuencia -tal y como podía observarse en la sección hecha por la excavadora- y la necesidad de acelerar los trabajos en la medida de lo posible por estar la construcción

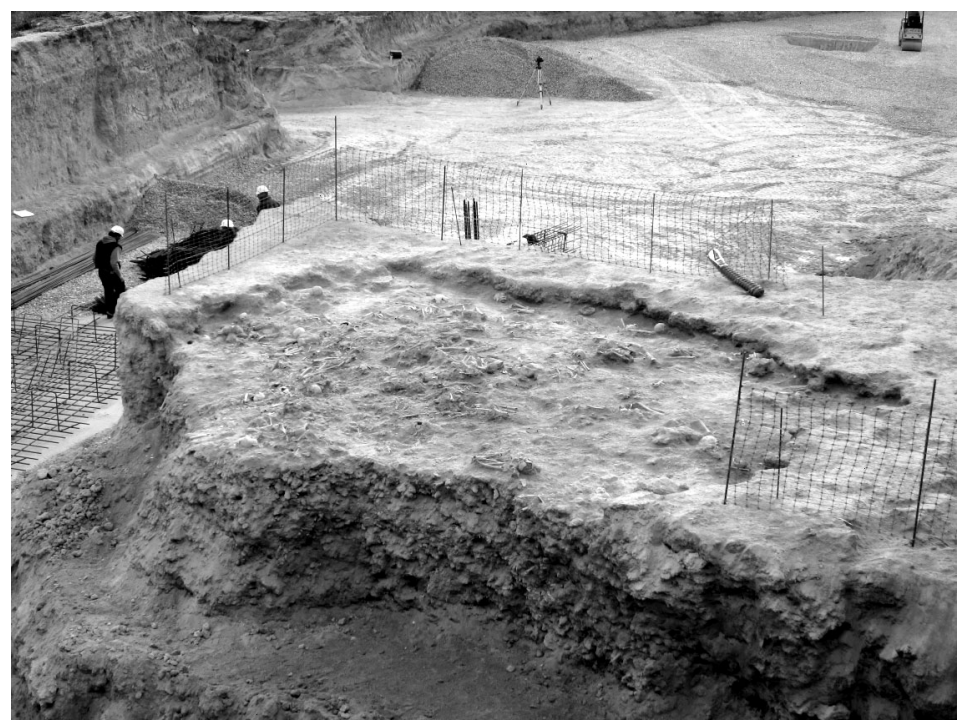

Lám. II. Vista general del yacimiento tras las primeras limpiezas. Obsérvese la sección realizada por la pala y la planta de la cueva.

T. P., 66, N. ${ }^{\circ} 2$, julio-diciembre 2009, pp. 143-159, ISSN: 0082-5638 doi: $10.3989 /$ tp.2009.09025 
de la promoción pendiente de los resultados de la intervención arqueológica, llevaron al diseño de una metodología que aunara la máxima precisión en el registro con la mayor rapidez posible del proceso de excavación.

En un primer momento se planteó la posibilidad de diseñar una cuadrícula aérea que, sujeta a la estructura metálica que cubría el yacimiento, proporcionase una georreferenciación fiable del registro, reticulando la superficie de excavación en unidades de $1 \mathrm{~m}^{2}$ y cada una de éstas, a su vez, en cuatro sectores menores, siguiendo la metodología puesta en práctica en yacimientos similares como Mussol y Carritx (Lull et al. 2001) y descartando desde el principio el dibujo directo de las evidencias, como en su día se hizo en San Juan Ante Portam Latinam (Vega 1999), pues no garantizaba la suficiente precisión para este tipo de excavaciones.

Sin embargo, la adopción de un sistema fijo de cuadrículas planteaba varios problemas. La alta densidad de restos antropológicos hacía fácil que muchos individuos o paquetes óseos quedaran distribuidos entre varias unidades de registro contiguas y no en una sola unidad, como parecía aconsejable. Además, una cuadrícula fija iba a obligar a realizar continuas comprobaciones, ralentizando de manera notable el trabajo de documentación gráfica, del que a su vez iba a depender el de excavación.

Ante esta situación, se optó por una solución novedosa que logró aunar la mayor velocidad posible de excavación con un registro de la máxima fiabilidad. Para ello se construyó un bastidor metálico móvil de $1 \mathrm{~m}$ de lado y dotado de cuatro pequeñas patas bajo sus vértices, que constituiría la unidad mínima de registro, y se instaló de manera permanente una estación total, así como un ordenador y una impresora a color en una caseta aneja a la excavación, procediéndose del siguiente modo:

1. Excavación de un área cualquiera del yacimiento siguiendo para ello conexiones anatómicas o agrupaciones significativas de huesos.

2. Colocación del bastidor metálico sobre esa superficie, sin atender a ninguna orientación predeterminada y cuidando de mantenerlo en una posición aproximadamente horizontal (4).

(4) El bastidor se construyó con pletina metálica hueca de sección cuadrada y $1,5 \mathrm{~cm}$ de anchura, pintándose los decímetros en bandas rojas y blancas alternas. En cuanto a las patas, se optó porque fuesen fijas, complementándose a veces con la colocación en su base de tacos de madera para lograr una estabili-
3. Con una cámara digital instalada en el extremo de una pértiga telescópica y accionada con mando a distancia se fotografía cenitalmente el bastidor (5), otorgándole a la fotografía una numeración que se corresponde con su número de cuadrícula, correlativa respecto a las imágenes previas y sin relación alguna con su ubicación concreta.

4. Con la estación total se georreferencian los cuatro vértices del bastidor (6).

5. El archivo de la imagen fotográfica, así como los datos de los cuatro vértices, se exportan al ordenador.

6. Con un programa de ortocorrección (7) se altera la imagen, de manera que el bastidor recupera la forma de un cuadrado perfecto (obviamente, los límites de la fotografía adquieren forma trapezoidal), corrigiéndose así la distorsión inicial de la imagen.

7. Corregida la imagen, se marcan los cuatro vértices del bastidor en la fotografía y se proporciona a Autocad la georreferenciación exacta de los mismos.

8. Desde Autocad se importa la imagen, que se coloca automáticamente en el lugar que le corresponde gracias a la georreferenciación de los vértices.

9. Con la ayuda de una tabla de digitalización se procede al dibujo arqueológico del cuadrado fuera de la excavación y como labor independiente de la continuación de los trabajos de campo (Lám. III).

10. La imagen ortocorregida se imprime en color, se anota el número del cuadro, la fecha y las coordenadas de sus cuatro vértices, y se procede al levantamiento de las evidencias fotografiadas, haciéndose sobre el papel anotaciones de cota referidas a las mismas, de forma que queden reflejadas las diferencias que puedan existir en el interior del cuadro, si un hueso está horizontal o inclinado, etc., así como si hay restos de cultura material.

dad óptima; se desechó la posibilidad de patas telescópicas por la pérdida de tiempo que podía suponer la regulación de las mismas para cada caso.

(5) Se buscó una cámara digital que tuviese una definición aceptable pero que al mismo tiempo fuera muy manejable, pesara poco y tuviese accionamiento a distancia. Se optó en este caso por una cámara Pentax A40 de $12 \mathrm{Mpx}$.

(6) La estación, modelo TopCom GPT-7005, se instaló cerca del área a excavar, a una distancia de entre 5 y 9 m, según sectores.

(7) Se utilizó el programa Perspective Rectifier v.3.3, que se comercializa con dos versiones, una profesional para trabajos de arquitectura, y otra más sencilla cuya licencia es realmente barata (50 euros en 2008), que fue la empleada en este caso y cuyas prestaciones cubrían con creces nuestras necesidades. 


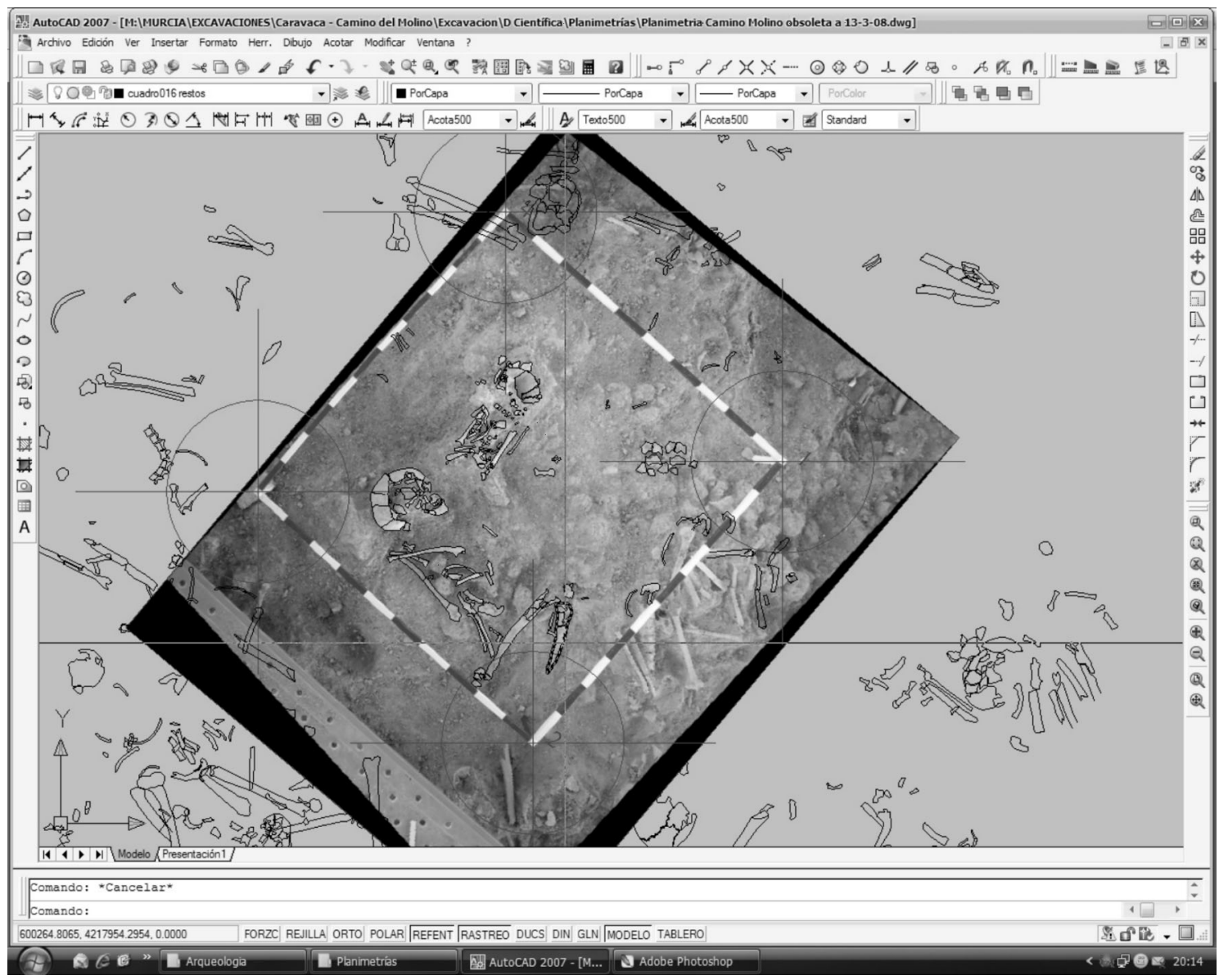

Lám. III. Proceso de dibujo a partir de una imagen digital cenital ortocorregida.

De este modo se logró un registro actualizado de la excavación y muy fiable tanto en su definición como en su georreferenciación, y el ritmo de excavación no estuvo sujeto a la lenta labor de dibujo, por otra parte ampliamente superada en cuanto a su precisión, pudiendo excavarse simultáneamente diversos sectores del yacimiento. La exhumación de restos se hizo siempre bajo la supervisión directa de una antropóloga que iba anotando en la impresión a color del cuadro cuantas observaciones estimaba convenientes, así como el número de inventario, y marcaba el ritmo de los trabajos.

Respecto al inventario de evidencias, a los huesos aislados y sin conexión anatómica se les asignó una numeración única (un hueso, un número), mientras que cuando formaban paquetes o estaban en posición anatómica se dio un número al conjunto; obviamente, los restos se empaquetaron de igual modo, anotándose en la caja los números que contenía, agrupándose las bolsas a su vez en una mayor que acogiera todos los restos óseos del mismo individuo y/o del cuadro. Con la cultura material se obró como es habitual, individualizando las evidencias.

Durante el proceso de excavación se separaron y/o recogieron además diversas muestras que previamente se habían catalogado como de interés para el estudio del yacimiento, principalmente de sedimento para diferentes estudios (paleodieta, granulometría, sedimentología, parasitología, etc.) y concentraciones de carbones. Además, se apartaron para su ulterior flotación y estudio antracológico $5 \mathrm{~m}^{3}$ de sedimento.

Con respecto a los medios materiales empleados durante la labor de excavación, aparte del uso cotidiano de punzones de madera y pinceles finos que minimizasen el daño sobre el registro óseo, la limpieza de las áreas de trabajo y la retirada de sedimento se realizó casi exclusivamente mediante el empleo de cinco aspiradores industriales 


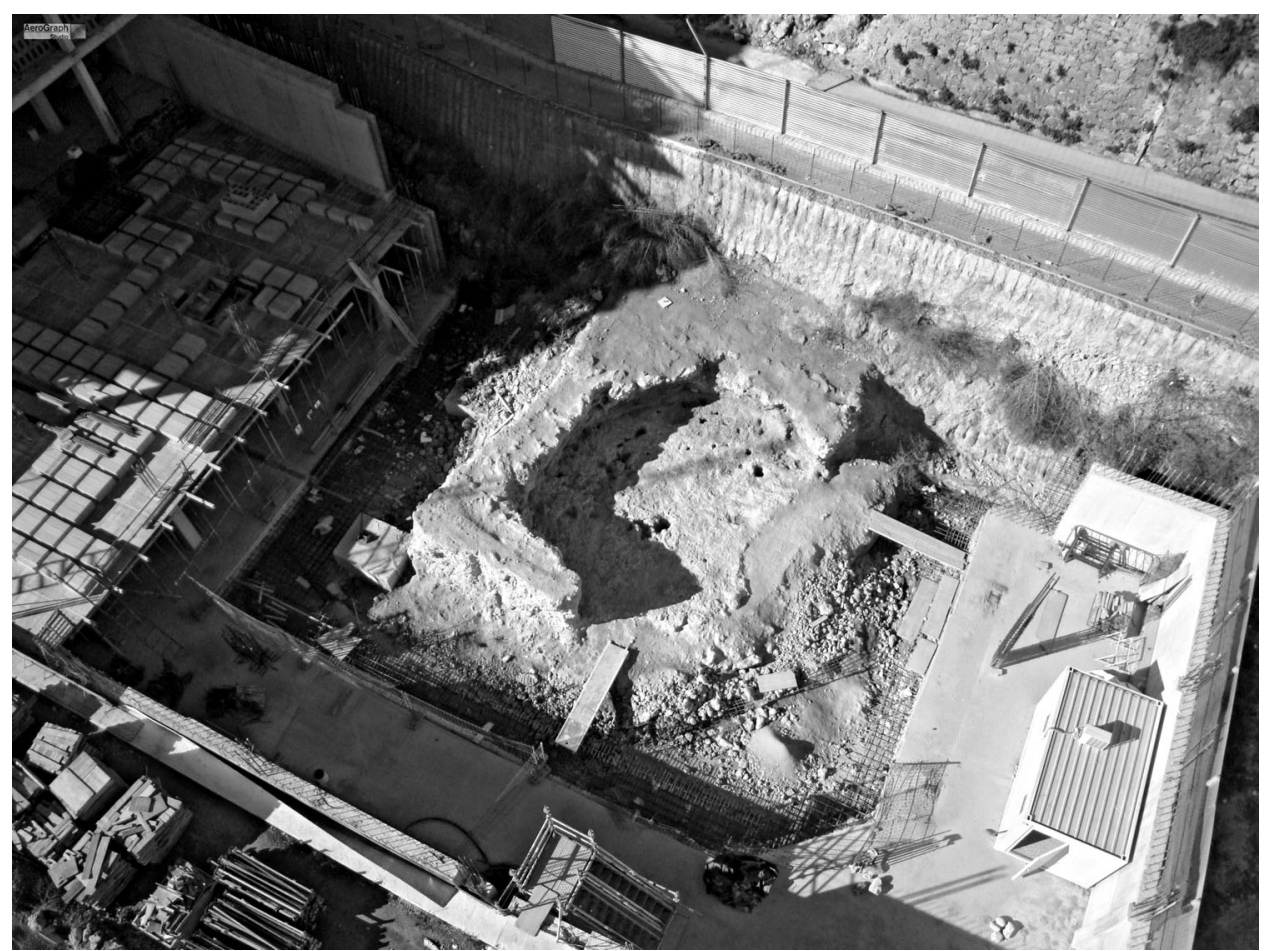

Lám. IV. Vista aérea del enterramiento de Camino del Molino una vez finalizada la excavación.

móviles y con velocidad regulable; su uso permitió agilizar enormemente el trabajo de excavación y solucionar muchos problemas de extracción de sedimento entre huesos, así como disponer continuamente de una superficie limpia y susceptible de ser fotografiada en condiciones óptimas.

Al término de la campaña se habían otorgado algo más de 1700 números de cuadro. Sirva como dato indicativo del volumen de trabajo que los restos óseos, una vez embalados, se almacenaron en cajas de cartón que sumaron $500 \mathrm{~m}^{3}$, mientras que la cultura material cupo en sólo 10 cajas que sumaron cerca de 1,5 $\mathrm{m}^{3}$. Estos datos permiten dar una idea del volumen de material recuperado y de la infraestructura necesaria que han generado los trabajos. Finalizada la excavación, y dado que el yacimiento iba a ser desmontado de manera inminente, se efectuó un escaneo 3D de toda la cavidad, tarea realizada por un equipo de la Universidad de Granada que se ofreció a colaborar en esta fase de documentación final del yacimiento (8).

(8) Agradecemos la disponibilidad del Dr. Esquivel, del Departamento de Prehistoria de la Universidad de Granada, que se ofreció a realizar esta tarea.

\section{DESCRIPCIÓN DE LA ESTRUCTURA FUNERARIA}

Originalmente el yacimiento consistió en una cueva natural formada en los travertinos por disolución y derrumbamiento progresivo de parte de sus paredes, retocándose posteriormente tanto éstas como el suelo hasta darle una apariencia similar a un fondo de cabaña (Lám. IV). La base, plana y con una inclinación apenas perceptible, tenía un diámetro próximo a los $7 \mathrm{~m}$, y la altura completa de la cavidad se estima en $4 \mathrm{~m}$ de los que sólo se conservan los dos inferiores. En el centro de la cubierta, hacia la que convergían las paredes, debió existir una abertura de unos 2-3 m de diámetro por la que penetró directamente agua de lluvia a lo largo de toda la secuencia de uso del lugar, como se ha podido constatar en el estudio sedimentológico del depósito situado en el centro de la cueva. Tanto por esa abertura como por al menos dos pequeños sifones laterales penetraron además aguas de escorrentía que aportaron una sedimentación con acumulación de gravas de diverso gramaje, en mucha menor medida lodos, dándose la particularidad de que el lugar debió 
anegarse con frecuencia durante su dilatado uso como área sepulcral.

El suelo presentaba un piqueteado que afecta a toda su superficie, sobre el cual se extendió una fina capa de arcilla amarilla de 1-2 $\mathrm{cm}$ de espesor. Encima de este suelo se realizaron tres fuegos que generaron una capa homogénea de carbones de igual espesor, sobre los que se colocaron fragmentos de cerámica en posición horizontal, normalmente correspondientes a vasijas de almacenaje, formando un pavimento continuo a partir del cual se inició la colocación de los cadáveres.

Además, en el suelo se identifican diversas perforaciones cilíndricas de diámetro variable. La mayor de ellas, de $35 \mathrm{~cm}$ de diámetro y 55 de profundidad, se ubica en el centro geométrico de la cueva, mientras que el resto parece dibujar un imperfecto semicírculo paralelo a la pared septentrional de la cavidad y distante de ésta en torno a $1 \mathrm{~m}$, y algunos agujeros de poste más aparecen pegados a la pared en ese mismo sector. Provisionalmente entendemos que todas estas perforaciones pudieron sustentar una estructura de madera que facilitara el acceso a la cueva desde la abertura superior, ya que la propia sedimentación y la potencia estratigráfica del enterramiento hacen que descartemos una entrada lateral que habría quedado totalmente colapsada. Durante la excavación se localizaron varios fragmentos de barros endurecido con improntas de maderas y otras fibras vegetales, que pudieron formar parte de esa posible estructura de acceso.

\section{SECUENCIA DE ENTERRAMIENTO}

La fosa albergaba en su interior un depósito de $1,70 \mathrm{~m}$ de potencia, no observándose en la sección hecha por la excavadora la existencia de hiatus, sino más bien una secuencia continua de deposición de restos humanos, frecuentemente intercalada por breves y localizados episodios de inundación parcial por aguas de escorrentía y, a lo sumo, dos posibles momentos de regularización de la superficie, quizás vinculados a sendos episodios de pequeños derrumbamientos que, por otra parte, se produjeron también esporádicamente a lo largo de toda la secuencia. Aunque la mitad superior de la cueva desapareció a inicios del siglo XX, parece que apenas se alteró el depósito de su interior, por lo que la secuencia parece completa.
Las primeras dataciones absolutas, así como la colocación de los individuos y la ulterior reubicación de parte de los mismos, permiten plantear un uso del lugar como lugar de deposición continua de individuos completos, muchos de ellos sujetos a fenómenos de recolocación, al margen de otro tipo de movimientos postdeposicionales que pudieron producirse de manera fortuita o intencional, como veremos.

Bajo este marco general, conviene insistir en tres cuestiones que consideramos fundamentales para la comprensión del yacimiento: el número de inhumados, la composición de los mismos y la escasez de elementos de ajuar.

A falta aún de un estudio detallado, actualmente en curso, se ha hecho una estimación provisional a partir del recuento de cráneos humanos que permite calcular un NMI de 1300, cifra que escapa a cualquier tipo de comparación con otros yacimientos de igual cronología a nivel peninsular y europeo. A estas evidencias antropológicas hay que sumar restos de, al menos, 50 cánidos completos que también formaron parte del ritual de enterramiento.

Un segundo rasgo destacable es la composición de ese registro antropológico. A tenor de las observaciones preliminares hechas durante la excavación, estamos ante la representación de una población calcolítica completa. A falta de los resultados definitivos, en torno al $30 \%$ corresponde a población infantil (Infantil $1+$ Infantil 2, esto es, menores de 14 años), incluidos neonatos, mientras que el resto de evidencias pertenece a todos los sectores de edad y tanto a mujeres como a hombres.

La tercera cuestión relevante, que supone también un rasgo distintivo del yacimiento, es la escasez de elementos de acompañamiento. La comparación con cualquier otro enterramiento múltiple nos lleva a afirmar que, desde este punto de vista, el ajuar es muy escaso y que la inmensa mayoría de inhumados no se acompañaron de ningún objeto. Téngase en cuenta que el enterramiento no está expoliado y que, exceptuando ese $15 \%$ destruido durante su descubrimiento, la excavación ha afectado a un registro aparentemente intacto desde un punto de vista arqueológico.

Se inicia la secuencia depositando individuos completos sobre el suelo de la cámara pero de forma mayoritariamente perimetral, junto a las paredes de la misma, documentándose pequeñas recolocaciones en forma de desplazamientos late- 


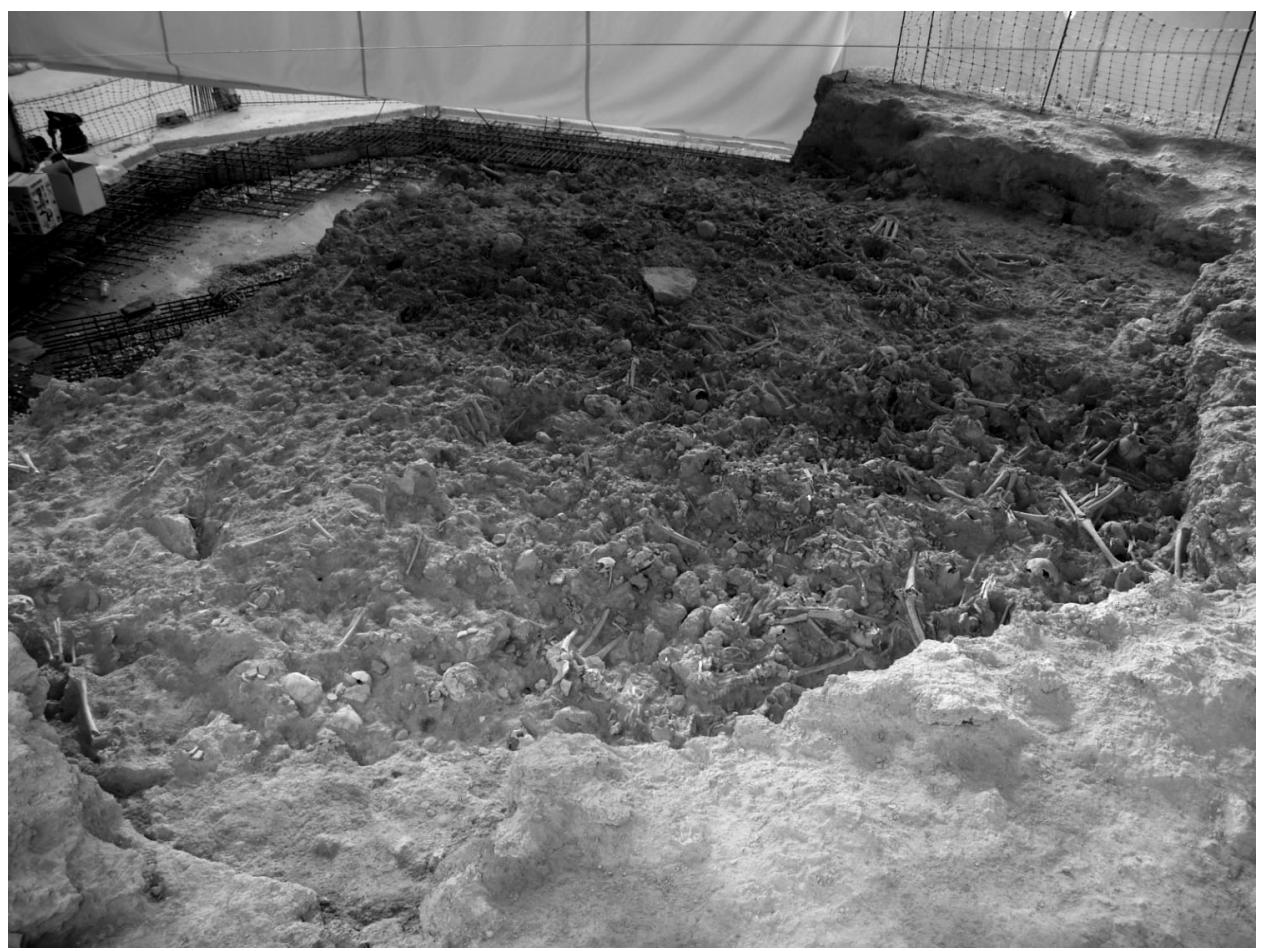

Lám. V. Vista general del enterramiento de Camino del Molino en pleno proceso de excavación. Obsérvese la densidad de restos antropológicos, así como el alto índice de astillamiento en la zona central del mismo.

rales para la acomodación de sucesivas deposiciones y quedando libre de restos toda la zona central de la oquedad.

Dicha dinámica se prolonga en el tiempo, realizándose sucesivas colocaciones sobre las áreas en las que previamente ya se habían depositado otros individuos (Lám. V). Aparentemente, conforme dicho anillo perimetral experimenta una acumulación excesiva de restos (salvo que exista una causa ritual que se nos escapa), numerosos restos de individuos ya no sólo son desplazados lateralmente sino que se reubican directamente en el centro de la cavidad. De este modo se inicia un doble proceso de acumulación:

a. Por una parte, se colocan restos "en primera inhumación" sobre todo junto a las paredes y junto o encima de individuos anteriores, generándose una cierta estratigrafía vertical a base de colocaciones en horizontal de individuos.

b. Al mismo tiempo, algunos de los restos de individuos anteriores, como consecuencia de la reestructuración de los espacios, son parcial o completamente reubicados -ya no hablamos de desplazamientos laterales- en el centro de la cá- mara, dispuestos sin orden aparente. Estos restos, en disposición caótica, sufren un índice de astillamiento muy superior a los ubicados cerca de las paredes, abundando las fracturas por flexión en huesos largos, que atribuimos al tránsito sobre ellos, documentándose incluso aplastamientos de algunos cráneos, si bien es cierto que la mayoría de ellos se reubican y preservan junto a las paredes del sepulcro (Lám. VI).

De este modo se fue originando en el centro de la cámara una acumulación anárquica de restos humanos y animales, así como de algunos objetos de ajuar. Desde un punto de vista sedimentario hay que destacar que este sector central de la cavidad está definido por una textura grumosa, con numerosos huecos entre los huesos; interpretamos estos rasgos en relación con el posible gran orificio central de la cubierta. Conforme se va generando esta acumulación central va aumentando igualmente la cota a la que se siguen colocando restos humanos en disposición primaria junto a las paredes, donde además se van recolocando la mayor parte de los cráneos de los individuos removidos anteriormente, siendo éste un rasgo tan 


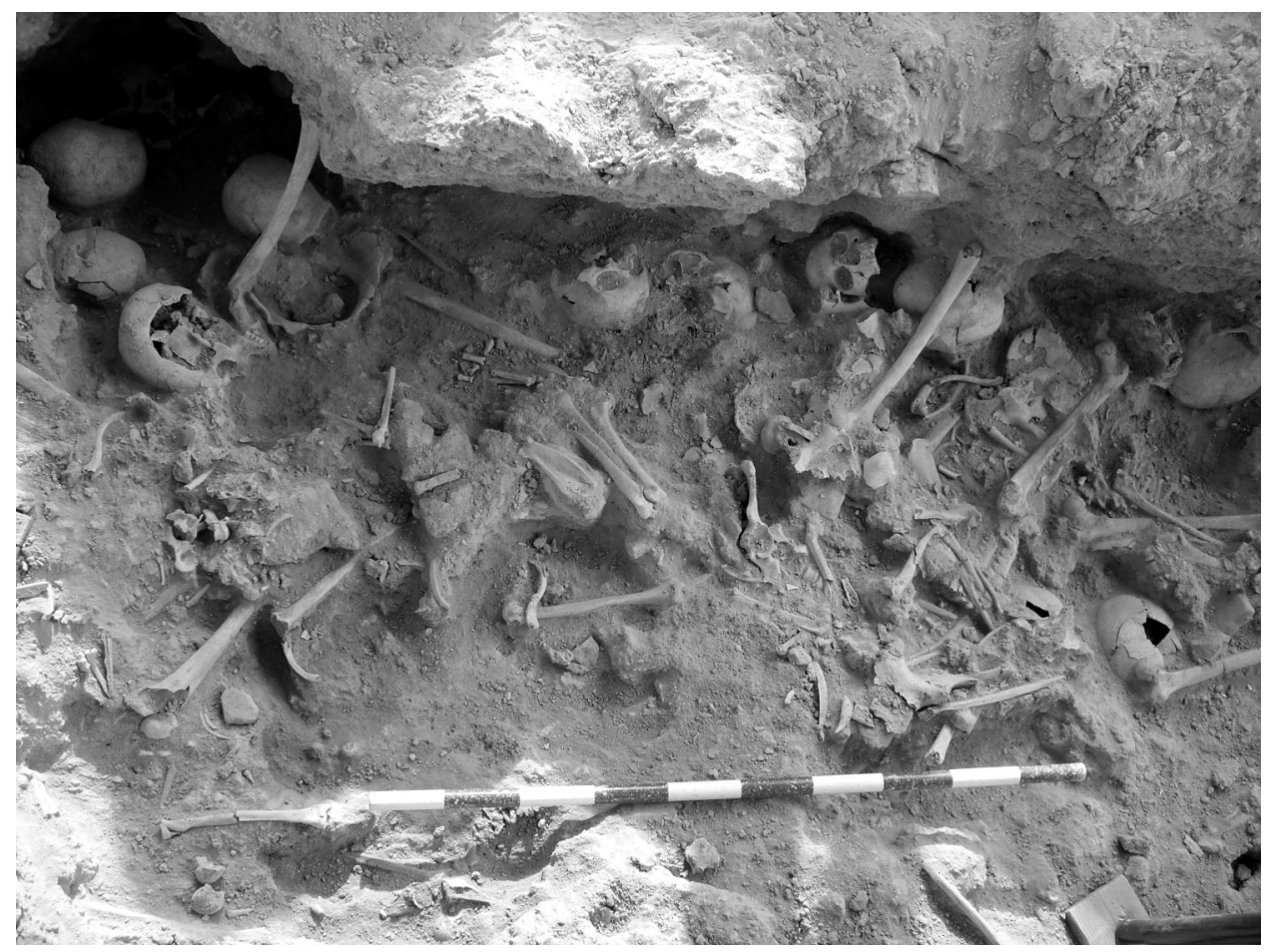

Lám. VI. Junto a las paredes de la cueva se acumulan los cráneos, junto con una mayor presencia de individuos en posición.

destacable a nivel general como la acumulación anárquica de huesos, muy fracturados, en el centro del sepulcro.

Ambos procesos -amontonamiento central y sucesivos depósitos primarios laterales- generan la progresiva colmatación de la cavidad mediante una estratigrafía apenas visible en la sección hecha por la excavadora, pero muy evidente si atendemos a las características del registro horizontal. Esta propuesta es además coherente con el planteamiento de una entrada a la cámara desde una posición elevada y que permitiera el acceso directo al área central, que actuaría como lugar desde el cual se redistribuyen los restos, tanto los de los últimos finados como los anteriores, siguiendo la dinámica ya comentada.

Conviene llamar la atención sobre el hecho de que en la zona central, aunque la mayor parte de restos carece de conexión anatómica y presenta un alto índice de fragmentación por flexión/aplastamiento, también encontramos otros que aún mantienen articulaciones parcialmente $y$, en unos pocos casos, algunos que configuran al individuo casi completo. En la base de esta zona, además, sí que encontramos algunos individuos en posición primaria.

De forma preliminar podemos decir que la reubicación de restos hacia el centro de la cámara, o los desplazamientos laterales en el área perimetral, se producen en muchas ocasiones cuando aún permanecen sin descomponer totalmente los tejidos blandos, pues se mantienen parcialmente las conexiones anatómicas. Además, queda abierta la posibilidad de que el mantenimiento de ciertas conexiones y posturas se deba a que aún se conservaban elementos que hicieran las veces de mortaja, siendo especialmente ilustrativos los casos en los que un individuo aparece con las piernas estiradas en direcciones diferentes pero manteniendo aún la conexión anatómica, mientras que brazos y antebrazos permanecen aún muy flexionados y adosados a restos de la caja torácica.

Esta dinámica se mantiene en la práctica totalidad de la secuencia, alterándose en su fase final, cuando la superficie completa de la fosa presenta individuos (humanos y cánidos) en posición anatómica y las remociones podrían deberse exclusivamente a fenómenos de tipo tafonómico. 
Durante la excavación se ha detectado una alta presencia de pequeños carbones, e incluso en alguna ocasión restos óseos que han sufrido de manera muy puntual la acción directa del fuego. A falta de que se proceda a la caracterización de los restos antracológicos, planteamos la posibilidad de que formen parte de teas que mantuvieran a las alimañas alejadas del enterramiento, que participasen de algún tipo de estrategia profiláctica o que simplemente facilitaran la visibilidad en el interior de la cueva.

Provisionalmente no se observan diferencias en la cultura material entre el último momento de uso y los anteriores, mientras que sí que ha cambiado la dinámica deposicional, de forma que la diferenciación entre la acumulación central y las disposiciones laterales queda desdibujada en el último momento de uso del enterramiento, mientras que se sigue apreciando un aspecto grumoso en el sedimento ubicado en el área central del sepulcro, que se correspondería con la abertura cenital, por lo que de ser correcta esa reconstrucción su existencia sería común a toda la vida útil de la cavidad.

En cuanto a la disposición de los restos individuales, la colocación primaria responde mayori- tariamente a la posición clásica de cuerpo flexionado con los brazos y antebrazos plegados sobre sí y apoyados sobre el tórax, con las manos entre el mentón y el esternón, y las piernas flexionadas sobre el abdomen, menos la derecha que la izquierda, apoyándose todo el cuerpo en el suelo sobre este último costado. Sólo tenemos certeza sobre posiciones primarias en este tipo de disposiciones, mientras que el resto pueden ser también debidas a movimientos postdeposicionales, destacando entre éstas la de algunos individuos con piernas articuladas pero sin posición determinada, mientras que brazos y antebrazos permanecen flexionados sobre el tórax. De forma minoritaria se localizan individuos que se disponen en posiciones que entendemos como atípicas, tumbados e incluso boca abajo. Particular es el caso peculiar, por ejemplo, de un individuo depositado en los primeros momentos de uso funerario del lugar, colocado boca abajo directamente sobre el suelo de la cámara y con los brazos cruzados sobre el sacro a la altura de las muñecas, adoptando una postura que se corresponde perfectamente con la característica de un individuo maniatado a la espalda (Lám. VII).

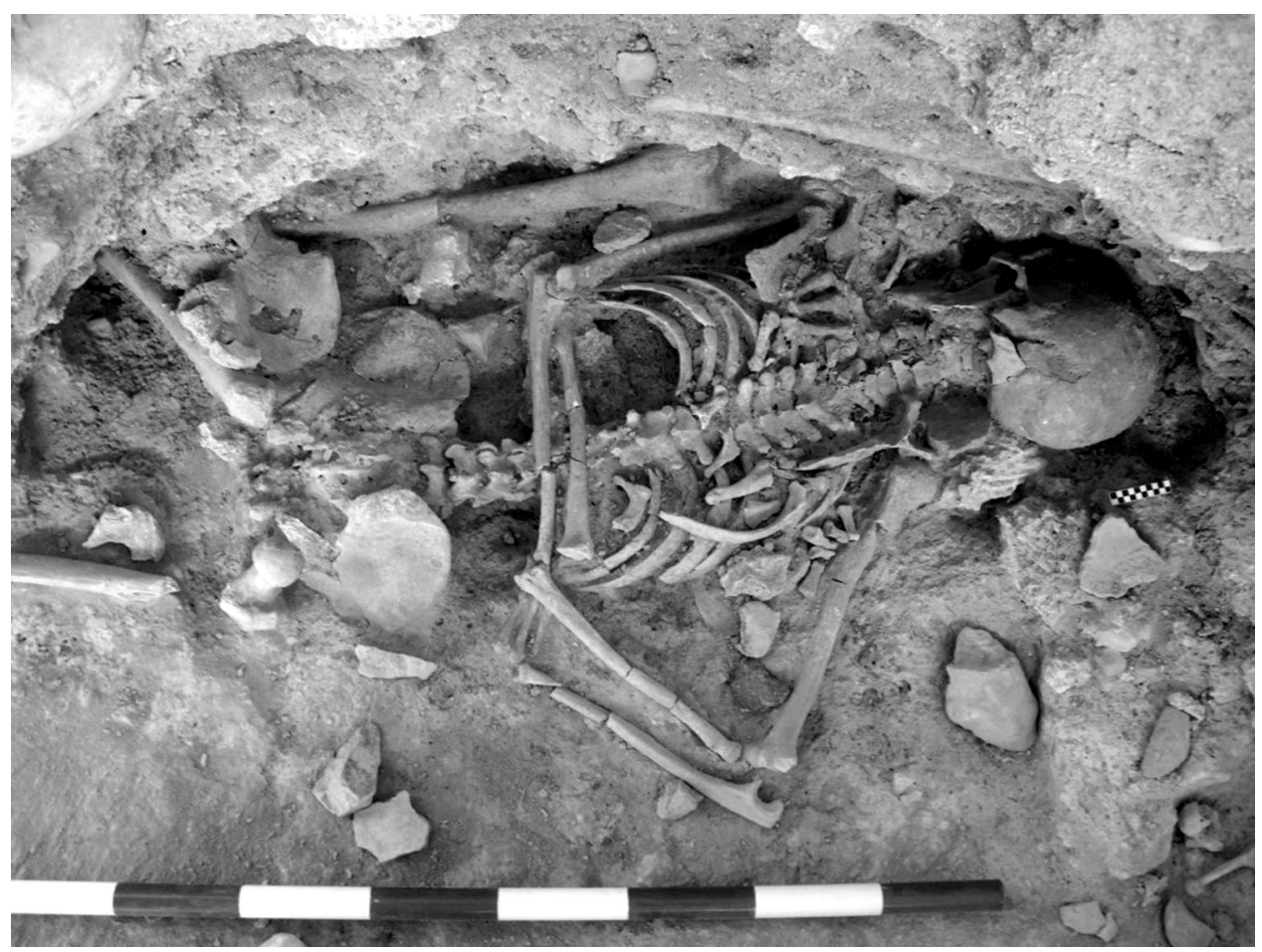

Lám. VII. Individuo n. ${ }^{\circ}$ 123, situado directamente sobre la base de la cavidad, en una posición original anómala y con los brazos cruzados a la espalda (Camino del Molino, Caravaca). 


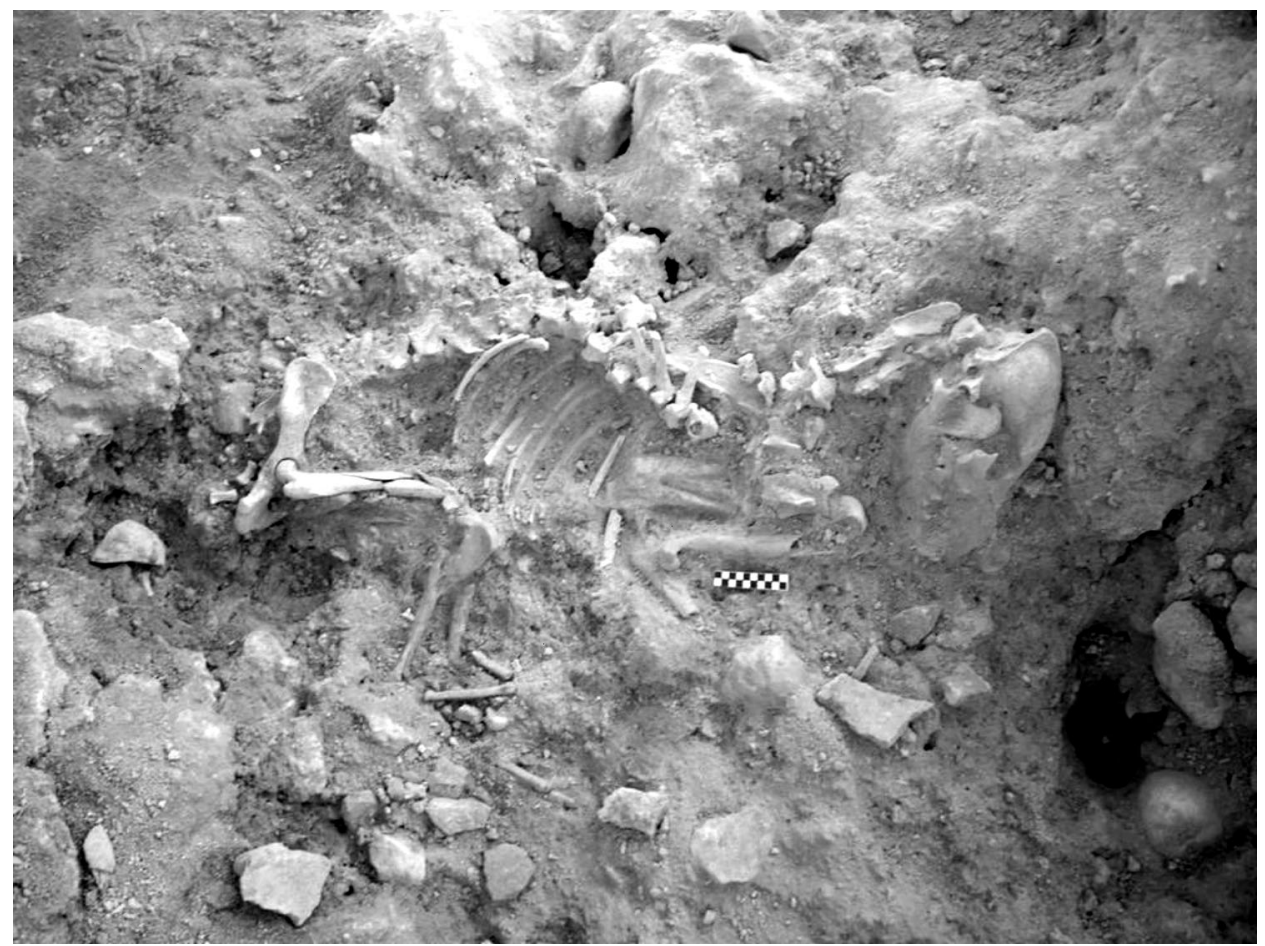

Lám. VIII. Cánido completo y en posición primaria.

Además del registro antropológico, es un elemento a destacar la presencia de cánidos completos (Lám. VIII), que encontramos a lo largo de toda la secuencia y sujetos a las mismas dinámicas que los restos humanos. Dichos individuos aparecen completos en la mayoría de ocasiones, o estando recolocados muestran evidencias de haber estado completos en su estado original, indefectiblemente en posición flexionada. Se documenta este tipo de ritual en el último momento de uso de la fosa, pero también en niveles inferiores, e incluso en la base de la secuencia.

\section{CULTURA MATERIAL}

Uno de los rasgos más llamativos del enterramiento de Camino del Molino es la gran escasez de ajuar funerario. La mayoría de inhumados carece de bienes de acompañamiento: varias decenas de vasijas cerámicas; 30 puntas de flecha, otras tantas láminas, un puñal y diversas tabletas retocadas, en sílex; en torno a 30 punzones y varillas planas, en hueso; 5 hachas pulimentadas; diversas cuentas de collar pertenecientes a unos pocos collares; y en metal 17 punzones de sección cuadrada (uno de ellos aún enmangado en una tibia de perro) (Lám. IX), una punta y un magnífico puñal de lengüeta de $32 \mathrm{~cm}$ de longitud. Quedan fuera de este cómputo, obviamente, los fragmentos cerámicos empleados para el pavimento de base del enterramiento.

Entre las vasijas del ajuar destacamos varias piezas carenadas que formalmente responden a lo que habitualmente consideramos como tulipas argáricas, de dimensiones muy reducidas, situadas en la parte superior de la secuencia (Lám. X), y de las que encontramos paralelos en el enterramiento calcolítico de Cueva del Calor (Cehegín) (Martínez Sánchez y San Nicolás del Toro 1993), en los Abrigos del Pozo (Calasparra) (Martínez Sánchez 1994) y en el megalito de Murviedro (Lorca) (Idáñez 1987), interpretados hasta ahora como intrusiones argáricas, algo que a tenor de los hallazgos en Camino del Molino debe ponerse en tela de juicio, pues queda constatada su vinculación a contextos claramente calcolíticos. Los yacimientos citados están, respectivamente, a dos horas, a una y a dos jornadas de camino a pie. No hay cerámica decorada, a excepción de un vaso con chevrons horizontales incisos (Lám. XI) cuya silueta es idéntica al conocido vaso de 


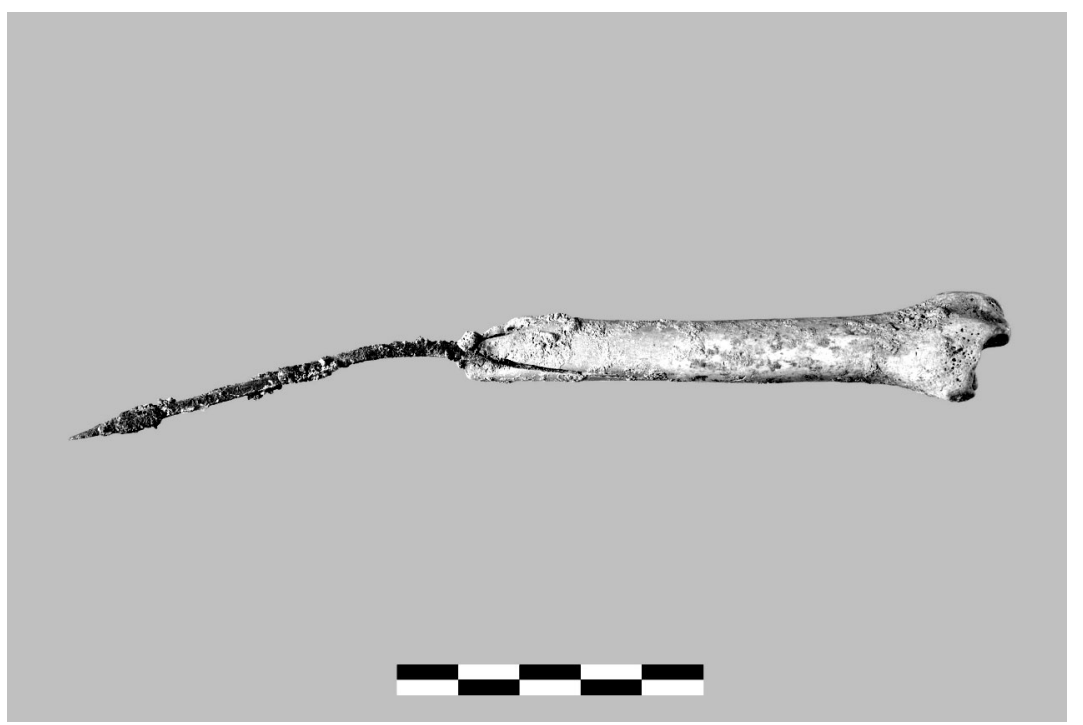

Lám. IX. Punzón de cobre de sección cuadrada, enmangado en una tibia de perro (Camino del Molino).

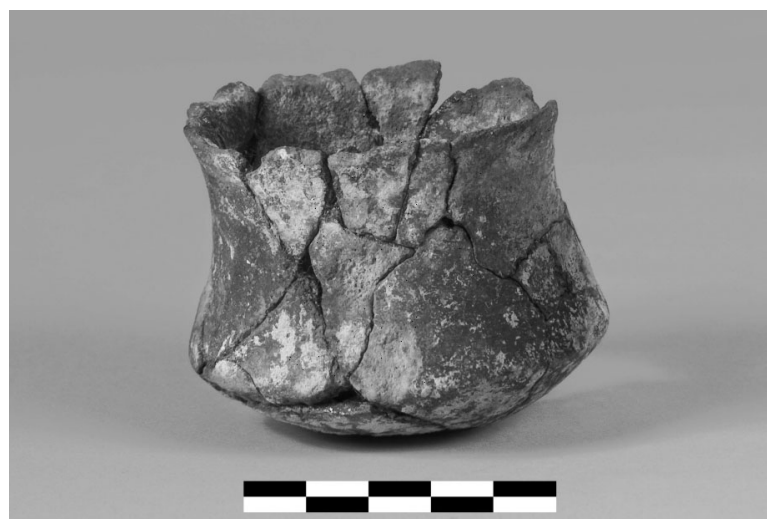

Lám. X. Vasito carenado, con cocción deficiente y de reducidas dimensiones (Camino del Molino).

carena baja y con decoración oculada de Los Millares, y algún fragmento cerámico con posibles triángulos incisos rellenos de puntos impresos (9). Excepto las citadas tulipas, el resto de vasijas presenta un elevado índice de fragmentación, acorde con los movimientos postdeposicionales detectados en el registro antropológico. Provisionalmente, y a la espera de finalizar su estudio, podemos estimar que quizás se alcance la cifra de dos centenares de vasijas.

(9) Actualmente se está procediendo a la limpieza e inventario de materiales, por lo que el trabajo de definición de vasijas completas está aún en curso, de manera que provisionalmente no es posible aportar más información en este sentido.

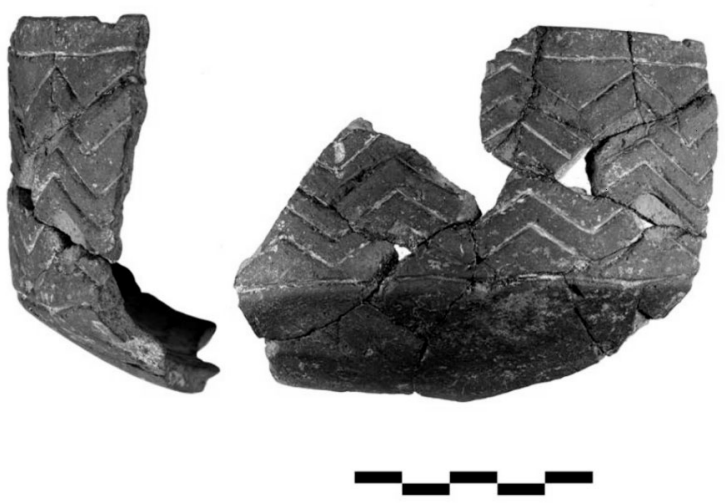

Lám. XI. Vaso con pseudocarena, en la base de la secuencia, con decoración de chevrons horizontales y línea incisa marcando la inflexión de la pared (Camino del Molino).

Entre los elementos de sílex destacan diversas puntas de base cóncava de cronología campaniforme, así como algunas de apéndices invertidos que también se consideran tardías (Soler 2002), en un contexto en el que predominan las foliáceas y las puntas de pedúnculo y aletas muy desarrolladas. Otro elemento de sílex de interés es un puñal o alabarda sobre tableta de más de $30 \mathrm{~cm}$ de longitud (Lám. XII), cuyos bordes presentan un retoque simple profundo y bifacial que da lugar a sendos filos rectilíneos que convergen en un extremo aguzado. Este tipo de soporte tabular es abundante tanto en el enterramiento como en el 


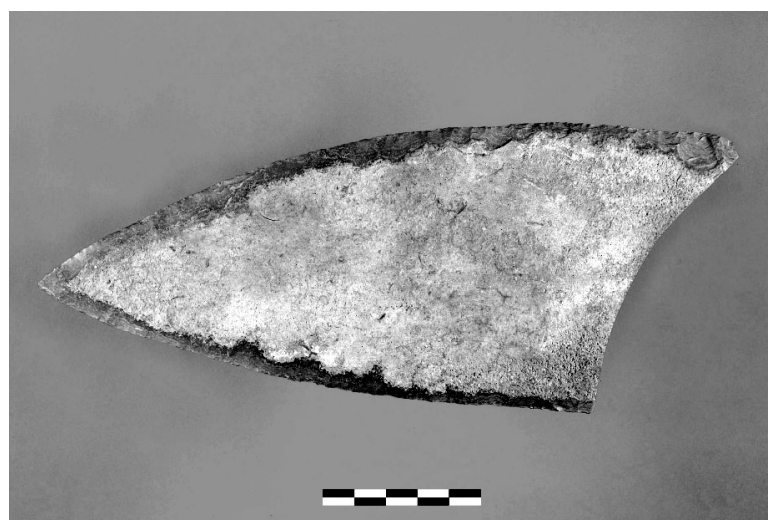

Lám. XII. Alabarda de sílex tabular.

hábitat asociado, en forma de fragmentos de puñales y alabardas, así como de piezas retocadas sin adscripción tipológica clara. El uso de tabletas de sílex y calcita es relativamente frecuente en yacimientos del interior murciano, sobre todo en fechas avanzadas del Calcolítico, pudiendo proceder de diversos afloramientos del área de Archivel, a una jornada al oeste del yacimiento, o de Jumilla, a dos jornadas hacia el este. Junto a estos materiales encontramos una treintena de láminas completas, dos de ellas raspadores, así como diversos fragmentos laminares y numerosas lascas de sílex de pequeñas dimensiones y sin retoque, un rasgo éste característico de numerosos enterramientos calcolíticos de la zona (Lomba 1995).

Con respecto a las cuentas de collar, la mayoría presentan la tipología habitual plana de sección de cilindro, estando confeccionadas en concha y piedra, destacando un conjunto formado por unas 50 piezas tubulares realizadas en hueso de ave, trabajadas en sus extremos, y que apare- cieron concentradas principalmente sobre el tórax de un individuo.

Actualmente todo este material se encuentra en proceso de estudio, por lo que la información disponible es aún escasa.

\section{CRONOLOGÍA}

Durante el proceso de excavación se han enviado nueve muestras para datación radiocarbónica, tres de ellas ya fechadas, y en los próximos meses se enviarán quince más. Las tres sirven para datar provisionalmente el inicio y final de la secuencia, así como un momento intermedio de la misma (Tab. 1). La primera muestra corresponde a un hueso humano de la base del enterramiento $\mathrm{y}$, por tanto, se asocia al inicio de la secuencia; la segunda, sobre astrágalo, se tomó a $+83 \mathrm{~cm}$ respecto a esa base, y la tercera, sobre el mismo tipo de hueso, a $+104 \mathrm{~cm}$. Así, y a la espera de confirmación con el resto de muestras, desde el inicio de la secuencia y hasta que el depósito alcanzó una potencia de $105 \mathrm{~cm}$ transcurrieron apenas 300 años. Otro dato interesante es la proximidad de dos de las fechas, $3950 \pm 40 \mathrm{BP}$ y $3990 \pm 40 \mathrm{BP}$, entre las cuales median $38 \mathrm{~cm}$ en vertical, a pesar de lo cual se plantea una cierta incoherencia por ser la de cota superior 50 años anterior a aquélla que se encuentra por debajo. Aunque el margen de error permitiría admitir ese posible desfase cronológico, hemos de valorar que éste tenga un origen postdeposicional en relación con el fenómeno de acumulación progresiva de huesos en el centro de la cámara, de forma que es posible que la última fecha se corresponda realmente con un momento de inhumación sin-

\begin{tabular}{|c|c|c|c|c|c|c|c|c|}
\hline \multirow{2}{*}{ Muestra } & \multicolumn{2}{|c|}{ BP } & \multirow{2}{*}{ 13C/12C } & \multirow{2}{*}{ 15N/14N } & \multicolumn{4}{c|}{ Cal (a 2 sigmas) } \\
\cline { 2 - 6 } & media & convenc. & & & ANE & BP & ANE & BP \\
\hline \multirow{2}{*}{ Beta-244973 } & $4170 \pm 40$ & $4260 \pm 40$ & -19.4 & +9.5 & 2920 & 4870 & 2800 & 4740 \\
& & & & & 2870 & 4820 & 2780 & 4730 \\
Beta-244974 & $3850 \pm 40$ & $3950 \pm 40$ & -19.0 & +10.2 & 2570 & 4520 & 2500 & 4450 \\
& & & & & 2510 & 4460 & 2340 & 4290 \\
Beta-244975 & $3900 \pm 40$ & \multirow{2}{*}{$3990 \pm 40$} & -19.5 & +8.5 & 2580 & 4530 & - & - \\
& & & & & 2460 & 4410 & & \\
\hline
\end{tabular}

Tab. 1. Datos de las tres fechas $\mathrm{C} 14$, sobre hueso humano, procedentes del yacimiento. Todas las fechas de las últimas cuatro columnas son a 2 sigmas. 
crónico o ligeramente anterior al de la fecha de $3850 \pm 40$ BP. El estudio detallado de los individuos datados está actualmente en curso, junto con el de otras 18 dataciones de las que áun no tenemos resultados.

De las tres fechas disponibles, la más antigua de ellas corresponde al inicio de la secuencia y se ubica en un momento precampaniforme, pues en el entorno geográfico del Sureste sólo una fecha vinculada a campaniforme (Los Millares XIX) es anterior a la de Camino del Molino. Las otras dos están perfectamente dentro de lo que se espera para los materiales a los que se asocian, esto es, horizonte campaniforme, que en el caso que nos ocupa se traduce en los punzones de sección cuadrada, el puñal de lengüeta y algunas puntas de sílex.

Dado el carácter preliminar de este trabajo, preferimos no profundizar en la interpretación de estas fechas hasta que no conozcamos el resto de dataciones y hayamos procedido al estudio detallado del registro material. En esa línea, la referencia a algunas dataciones de otros yacimientos no pretende ser una relación exhaustiva sino tan sólo un marco general de referencia. No obstante, sí que pueden plantearse algunas cuestiones relativas a la interpretación general del yacimiento.

\section{UNA PRIMERA VISIÓN DEL YACIMIENTO: PROPUESTAS DE TRABAJO}

Varios son los rasgos que convierten a Camino del Molino en un yacimiento excepcional, no sólo por las evidencias que lo conforman sino también, y quizás principalmente, por los interrogantes que plantea.

El primer elemento que llama la atención es el elevado número de inhumados. Aunque se trate de una cifra provisional, 1300 individuos escapan a toda comparación: en San Juan Ante Portam Latinam (Laguardia, Álava) los restos representaban a 289 individuos (Vega 1999), y más lejos aún quedan los en torno a 200 de Can Martorell (Barcelona), también calcolíticos (Mercadal y Agustí 2003; Petit y Pedro 2005), y ya en la Edad del Bronce, los de Mussol y Carritx, en Menorca (Lull et al. 2001; Rihuete 2002). Ciñéndonos al Neolítico y Calcolítico, y hechas las referidas excepciones vasca y catalana, lo habitual es que los enterramientos múltiples, en recintos megalíticos o en cuevas, alberguen grupos de en torno a 5, 20-30 individuos, sobre 50, y muy excepcionalmente por encima del centenar de sujetos.

El ritual de enterramiento múltiple y extramuros, característico del Calcolítico de la zona, es interpretado comúnmente como resultado de la preponderancia del sentimiento de pertenencia al grupo (Matthers 1984) frente a la individualidad que veremos reflejada en la Edad del Bronce a través de las inhumaciones únicas, raramente dobles y excepcionalmente triples, habitualmente en el interior de los poblados y con mucha frecuencia bajo o junto a las viviendas. La reutilización de silos en el Calcolítico escapa obviamente a esta dinámica de enterramientos múltiples y extramuros, pero también es cierto que se adscribe a unas circunstancias muy concretas en las que aquí no podemos profundizar. No hay duda de que en esa ya larga relación de enterramientos múltiples está además presente solamente, como ocurre en época argárica, un pequeño sector de la población: "faltan" inhumados si comparamos el registro funerario con los hábitats con los que se relacionan. En Camino del Molino el panorama es muy diferente.

Además, aunque los datos sean provisionales, todo apunta a que están representados en amplias proporciones ambos sexos y todos los segmentos de edad, algo que parece indicar que no estamos ante una selección sino ante la totalidad o práctica totalidad de la población de Molinos de Papel (en el hábitat se han localizado unos pocos enterramientos individuales amortizando silos). La horquilla cronológica que indican las dataciones absolutas del enterramiento, combinada con el número de inhumados, podría estar apuntando, de ser cierta la hipótesis de que está representado casi el $100 \%$ de fallecidos, una población de alrededor de 70-80 personas que debieron depositar a sus finados durante cerca de 350 años.

El registro arqueológico del hábitat marca pautas similares a las observadas en el enterramiento, esto es, cronologías de finales del Calcolítico, con presencia de elementos del horizonte campaniforme, y ausencia por el momento de evidencias que permitan inferir grandes diferencias económicas y sociales, aunque se documentan tareas de índole colectivo de cierta entidad como la excavación de grandes fosos o la erección de estructuras que podrían interpretarse como defensivas, pero que en algunos casos son fosas por las que parece haber circulado agua. El 
referido horizonte campaniforme en el poblado se traduce en unos pocos elementos metálicos (punzones de sección cuadrada y puntas Palmela), también siguiendo el modelo del enterramiento.

La comparación entre hábitat y enterramiento permite provisionalmente plantear como hipótesis de trabajo que Camino del Molino albergó si no a toda, sí a buena parte de los antiguos pobladores del hábitat de Molinos de Papel, un asentamiento basado en actividades agropecuarias en el que, salvo algunos elementos aislados de metal que apuntan en otra dirección, la cultura material muestra una gran uniformidad. El estudio detallado de enterramiento y hábitat, en la perspectiva mencionada, es la primera de las distintas líneas de investigación que se abren tras los resultados preliminares de la excavación del enterramiento.

Desde esa misma perspectiva debemos señalar que en el hábitat, que se excava actualmente siguiendo los ritmos de urbanización de la zona, en algunas estructuras domésticas abandonadas se ha documentado un fenómeno de amortización como depósito funerario traducido en inhumaciones individuales con nulo o escaso ajuar, salvo un individuo que portaba un importante conjunto de marfiles con perforaciones en V (10). También se han localizado algunos restos de cánidos.

La ausencia o escasez extrema de ajuar, la propia disposición flexionada de los inhumados y la aparición de cánidos como parte del ritual funerario son tres elementos que abren una segunda línea de trabajo: cómo compaginar que un hábitat calcolítico, con un área sepulcral extramuros perfectamente definida y que parece aglutinar a la práctica totalidad de inhumaciones, realice inhumaciones intramuros con similar rito de enterramiento, salvando el hecho de que en un caso se trata de un enterramiento múltiple y en los otros de individuales ¿Está reflejando este hecho el momento de tránsito de la inhumación múltiple y extramuros a la individual y efectuada en el interior de los asentamientos? Las inhumaciones en silos y fondos amortizados de Molinos de Papel, ¿deben interpretarse como intramuros o quedan

(10) Para un estudio detallado de dicho conjunto se puede consultar López Padilla, J.A. (e.p.): "Dinámica de la Producción y consumo de marfil en el Sudeste y área Centro-Meridional del Levante Peninsular entre c. 2200 BC - c.1200 BC". En T.X. Schuhmacher y J.A. López Padilla (ed.): Marfil y Elefantes en la Península Ibérica y el Mediterráneo, MARQ, Museo Arqueológico de Alicante (26 y 27 de noviembre de 2008). Iberia Archaeologica 16 (1). Deutsches Archäologisches Institut MARQ. Diputación de Alicante. fuera del área doméstica una vez que ese sector se abandona en favor de otro adyacente y, en ese caso, sigue manteniéndose la dinámica de depositar a los fallecidos fuera del asentamiento, aunque aportándose como novedad el carácter individual del enterramiento? ¿Puede establecerse algún tipo de relación entre los individuos acompañados de cánidos aparecidos en el asentamiento y aquellos documentados en el enterramiento múltiple de Camino del Molino? ¿Por qué asistimos a una diferenciación ritual tan notable a la hora de seleccionar el lugar de enterramiento? El hecho de que encontremos en la cavidad objetos de elevado valor añadido (los elementos metálicos, el puñal-alabarda de sílex, y probablemente también los cánidos) pero que al mismo tiempo la proporción de ajuares sea muy baja descarta que sólo esté depositado un sector de la población.

Otro rasgo importante para la investigación es la documentación de inhumación de cánidos no en estructuras domésticas amortizadas para uso funerario sino en un sepulcro múltiple en toda regla y ubicado extramuros. Los paralelos de rituales funerarios que incorporan cánidos son ya numerosos en la mitad meridional de la Península Ibérica, pero siempre se circunscriben a silos y fondos de cabaña amortizados, pudiendo acompañar a inhumaciones individuales o de unos pocos individuos, e incluso se conocen casos de enterramientos exclusivamente de cánidos en los cascos urbanos de Lorca y Monteagudo, en Murcia. No son estos los únicos animales que parecen participar en las exequias como parte del ritual, pues también hay documentados en otros yacimientos ovicápridos, bóvidos e incluso équidos, si bien en Camino del Molino sólo hay cánidos, además de algún resto aislado de otras especies.

La presencia de cánidos se ha interpretado en relación con la ganadería (Cámara 2001: 108), una actividad que experimenta un incremento destacable conforme avanza el Calcolítico y que se convierte en una notable actividad económica durante la Edad del Bronce. Que documentemos este ritual en un enterramiento múltiple y extramuros puede estar reflejando el reconocimiento del valor de ese tipo de actividad económica en el seno de las comunidades calcolíticas del último tercio del III milenio a.C., y su inclusión en el sepulcro podría valorarse como un auténtico bien de prestigio, en una fase inmediatamente anterior al cambio de rito, de múltiple a individual y de extramuros a vinculado a estructuras domésticas diferenciadas de la colec- 
tividad del conjunto del asentamiento. Esta es una tercera línea de investigación vinculada a los resultados de la excavación.

Las fechas radiocarbónicas, pero sobre todo los movimientos postdeposicionales y la presencia de diversos sedimentos de escorrentía intercalados en la secuencia, descartan la posibilidad de que estemos ante un momento único de inhumación, algo que podría haber explicado la enorme cantidad de individuos e incluso la extrema escasez de bienes de acompañamiento. Sin embargo, aunque sean escasos, los hay, y si bien los objetos de hueso, metal y sílex, así como las cuentas de collar, podrían interpretarse como "elementos portables", esto es, que podrían simplemente formar parte del fardo funerario en tanto que pueden ser parte del adorno o de la panoplia personal, no es posible explicar del mismo modo los recipientes cerámicos, necesariamente depositados ex profeso en el interior de la fosa.

No obstante, sigue siendo atípica tanto la cantidad de individuos como el hecho de que aparentemente pueda estar depositada en Camino del Molino la práctica totalidad de la población. Es cierto que tendemos a interpretar este fenómeno como reflejo de un cierto tipo de sociedad, que en este caso incluiría a individuos señalados (los acompañados de perros y de elementos metálicos) pero en la que, por las razones que sean, prima la pertenencia al grupo del conjunto de habitantes del poblado, que básicamente no presentan una diferenciación social (práctica ausencia de ajuar o ausencia absoluta de éste), sea porque la diferenciación no es significativa, porque no es un elemento a tener en cuenta en el enterramiento, o simplemente porque no existe. En la idea de profundizar al respecto, se han diseñado una serie de estrategias con el fin de intentar detectar diferencias entre los inhumados: estudio de la helmintofauna -trematodos, cestodos y nematodos- de la población humana, análisis moleculares orientados a la detección de parasitosis sistémicas a partir de los restos de médula ósea, análisis de dieta mediante elementos-traza, y estudio de isótopos estables.

Desde una perspectiva más estrictamente arqueológica son varios los dilemas que plantea el yacimiento, sobre los cuales debemos hacer también algunas propuestas iniciales. La interpretación del yacimiento debe conjugar la constatación de "colectivismo" que hace prevalecer el concepto de pertenencia al grupo, con la presen- cia de elementos que claramente diferencian a algunos individuos. Si es cierta la vinculación de inhumaciones de cánidos junto a algunos individuos con la actividad ganadera, sin duda ésta tuvo una importancia notable entre los habitantes del poblado de Molinos de Papel, pues tanto en algunos silos amortizados en el área de asentamiento como en el propio sepulcro múltiple de Camino del Molino hallamos esta modalidad funeraria.

Aunque la cultura material es real y proporcionalmente escasa, plantea algunas cuestiones de interés, más allá de las ya comentadas en relación con unos u otros objetos en concreto. Una de ellas es la presencia de pequeñas vasijas carenadas que formalmente nos remiten directamente al concepto de tulipa argárica, una de ellas localizada en superficie y por tanto fuera de contexto pero proveniente del último momento de uso del enterramiento, mientras que la otra se vincula estratigráficamente a materiales del horizonte campaniforme y dataciones absolutas en torno a 3950 BP. Estando fuera de toda duda su contextualización, la aparición de esta última es una óptima sugerencia a indagar en el origen real de algunos morfotipos propios del mundo argárico en un contexto de Calcolítico Final en el que están aún vigentes todas y cada una de las formas y maneras preargáricas, tanto en lo que se refiere al modelo de enterramiento como a los materiales que se acompañan, sobre todo las puntas de flecha en sílex, uno de los grandes ausentes en los contextos de la Edad del Bronce, y las varillas planas de hueso. De momento queda abierta también la posibilidad de que estas vasijas sean alóctonas y provengan de lugares en los que ya se ha desarrollado lo que entendemos por complejo argárico, en cuyo caso deberíamos interpretarlas como elementos significados por su valor añadido, sin que entremos de momento en mayores consideraciones, pues dicho valor podría estar basado en la rareza de las piezas en el contexto geográfico de las tierras del interior, pero también podría justificarse si se relacionan con individuos de procedencia foránea, que se han enterrado también en Camino del Molino y que por tanto han penetrado en la red social de esa comunidad.

Con respecto al tratamiento dado a los restos humanos, en la fase en la que se encuentran los trabajos poco podemos decir. No obstante, sí que conviene insistir en que se mantiene esa cierta norma de deposición primaria en posición flexionada y habitualmente sobre el costado izquierdo, 
sujeta con frecuencia a remociones parciales o completas que parecen tener que ver con una adecuación del espacio que permitiera la continuación de los enterramientos pero, obviamente, garantizando el mantenimiento del vínculo espacial de los recién fallecidos con sus antepasados y congéneres, de ahí que aparentemente parezca que la totalidad de los restos, removidos o no, permanezcan en el interior de la fosa. En principio descartamos fenómenos de segunda inhumación y de selección de restos para constituir paquetes funerarios que, por otra parte, no se han localizado.

El hallazgo de Camino del Molino abre nuevas líneas de investigación en el Calcolítico de la zona. Por primera vez contamos con un registro poblacional prácticamente completo que permitirá, entre otros, estudios detallados sobre pirámides de muerte y rasgos antropológicos y paleopatológicos de una muestra muy significativa y que incluye ambos sexos y todas las edades de una población durante unos 350 años, además del análisis detallado de su ajuar y de rasgos relacionados con dieta y salud de esa población. Este trabajo tiene la pretensión de presentar el hallazgo, los primeros resultados y las orientaciones que están rigiendo su investigación.

\section{BIBLIOGRAFÍA}

Cámara Serrano, J.A. 2001: El ritual funerario en la Prehistoria Reciente en el sur de la Península Ibérica, British Archaeological Reports 913. Oxford.

Idáñez Sánchez, J.F. 1987: "Informe de excavación de urgencia realizada en la necrópolis eneolítica de Murviedro (Lorca)". Excavaciones y Prospecciones Arqueológicas, Servicio Regional de Patrimonio Histórico. Murcia: 93-102.

Lomba Maurandi, J. 1995: Las industrias líticas talladas del Eneolítico/Calcolítico en la región de
Murcia. Tipología, distribución y análisis contextual, Tesis Microfichada. Universidad de Murcia. Murcia.

Lull Santiago, V.; Micó Pérez, R.; Rihuete Herrada, C. y Risch, R. 2001: "Las cuevas de Es Carritx y Es Mussol (Ciutadella, Menorca): La Prehistoria de las Baleares a la luz de las tinieblas". En M. Hernández Pérez (ed.): Y acumularon tesoros: mil años de historia en nuestras tierras. Caja de Ahorros del Mediterráneo. Alicante: 87-102.

Pujante Martínez, A. 1999: "El yacimiento prehistórico de Los Molinos de Papel (Caravaca de la Cruz, Murcia). Intervención arqueológica vinculada a las obras de infraestructura del Plan Parcial SCR2, 1999-2000”. Memorias de Arqueología 14. Murcia: $133-172$.

Martínez Sánchez, C. 1994: "Nueva datación C14 para el Neolítico de Murcia: los abrigos del Pozo (Calasparra)". Trabajos de Prehistoria 51 (1): 157-162.

Martínez Sánchez, C. y San Nicolás del Toro, M. 1993: "La ocupación argárica de la Cueva del Calor (Cehegín). Campaña de 1990". Memorias de Arqueología 4. Murcia: 73-82.

Mercadal Fernández, O. y Agustí i Farjas, B. 2003: "Estudi paleoantropològic. La costa de Can Martorell (Dosrius, El Maresme). Mort i violència en una comunitat del litoral català durant el tercer mil.leni a.C.". Laetania 14: 75-116.

Petit, M.A. y Pedro, M. 2005: "Hipogeos durante el III milenio AC en el nordeste de la Península Ibérica". Mayurqa 30: 203-223.

Rihuete Herrada, C. 2002: Dimensiones bioarqueológicas de los contextos funerarios. Estudio de los restos humanos de la necrópolis prehistórica de la Cova des Càrritx (Ciutadella, Menorca), Tesis Doctoral en pdf, Universitat de Barcelona. Barcelona.

Soler Díaz, J.A. 2002: Cuevas de inhumación múltiple en la Comunidad Valenciana. Museo Arqueológico Provincial de Alicante. Alicante.

Vega Aramburu, J.I. 1999: El enterramiento neolítico de San Juan Ante Portam Latinam. Diputación Foral de Álava. Vitoria. 